\title{
The Lateral Thoracic Vessels: A Useful Recipient in Immediate Breast Reconstruction
}

\author{
Hui Chai Fong, MBBS, MRCS ${ }^{1}$ Terence Goh, MBBS, MRCS, MMed, FAMS ${ }^{1}$ \\ Christopher Hoe Kong Chui, MBBS, MRCS, MMed, FAMS ${ }^{1}$ Mohamed Zulfikar Rasheed, MBBS, MRCS, \\ MMed, FAMS ${ }^{1}$ Yee Siang Ong, MBBCHir, MRCS, MMed, FAMS ${ }^{1}$
}

${ }^{1}$ Department of Plastic Reconstructive and Aesthetic Surgery,

Address for correspondence Hui Chai Fong, MBBS, MRCS, Department Singapore General Hospital, Singapore

of Plastic Reconstructive and Aesthetic Surgery, Singapore General Hospital, J Reconstr Microsurg Open 2016;1:2-7.

\begin{abstract}
Background Appropriate recipient vessel selection is a crucial aspect of microsurgical reconstruction. The chest wall presents several options for microvascular anastomosis, the most popular being the internal mammary and thoracodorsal vessels, although they

Keywords

- lateral thoracic artery

- breast reconstruction

- recipient vessel

- deep inferior epigastric perforator flap

- transverse rectus abdominis myocutaneous flap may not always be available or suitable for breast reconstruction. We propose that the lateral thoracic vessels are a useful alternative, given their central position and intraoperative exposure in a skin-sparing mastectomy.

Methods and Results We have performed four abdominal flaps based on the deep inferior epigastric artery and lateral thoracic vessels as the recipient vessels. The average diameter of the lateral thoracic artery was $2 \mathrm{~mm}$ and the vein was $2.75 \mathrm{~mm}$. There were no vessel conversions, flap failures, or complications. Excellent aesthetic results were achieved. The anatomy of the lateral thoracic artery is described.

Conclusion The lateral thoracic vessels are advantageous and safe recipient vessels. Their consistent anatomy, central location, and intraoperative exposure make them useful recipient vessels in breast reconstruction.
\end{abstract}

The recipient vessel is a critical factor for success in any microvascular reconstruction. Spatial and functional constraints resulting from improper recipient vessel selection have significant impacts on reconstructive success and aesthetic outcome. The chest wall offers several options for anastomosis. The thoracodorsal ${ }^{1-4}$ and internal mammary (IM) vessels are particularly well described. ${ }^{5-7}$ However, these vessels may not always be available or suitable for anastomosis.

While various modalities for preoperative evaluation of recipient vessels exist, they may not accurately evaluate the extent of vessel damage. Klein and colleagues found that radiotherapy does not always cause angiographic or macroscopically obvious damage to the IM vessels; hence, radiation-induced atherosclerosis of the IM arteries cannot

received

July 10,2015

accepted after revision

August 30, 2015

published online

January 20, 2016 $10.1055 / \mathrm{s}-0035-1570535$ ISSN $2377-0813$. always be detected preoperatively by digital subtraction angiography or even by intraoperative examination. Furthermore, a normal angiogram does not rule out surgical insufficiency of the IM vein. ${ }^{8}$ As such, in patients who are undergoing secondary breast reconstruction after thoracic radiotherapy, preoperative angiography may not be a useful indication of vessel quality, and it may be necessary to use an alternate vessel should the thoracodorsal or IM vessels be unsuitable.

With the increasing popularity of skin- and nipplesparing mastectomy, ${ }^{9}$ we believe that the lateral thoracic vessels are well suited for this role. They are centrally located and easily dissected, and allow for ideal positioning of the breast mound within the envelope of a skin-sparing mastectomy (-Fig. 1).

Copyright $\odot 2016$ by Thieme Medical Publishers, Inc., 333 Seventh Avenue, New York, NY 10001, USA.

License terms

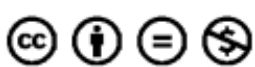




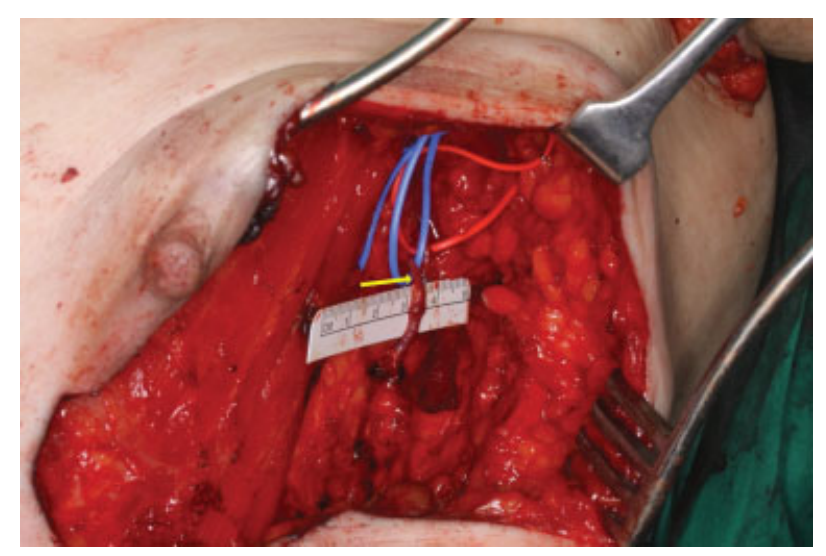

Fig. 1 The lateral thoracic artery and vein (arrow) are centrally located and easily dissected, and allow for ideal positioning of the breast mound within the envelope of a skin- or nipple-sparing mastectomy.

\section{Cases}

We have used the lateral thoracic vessels in two free transverse rectus abdominis myocutaneous (TRAM) flaps (-Figs. 2 and $\mathbf{3}$ ), one deep inferior epigastric perforator (DIEP) flap (-Fig. 4), and a supercharged pedicled TRAM flap (-Fig. 5) in primary reconstruction with good results. In these cases, the IM and thoracodorsal vessels were assessed to be adequate, but the decision was made to utilize the lateral thoracic vessels, owing to their excellent pressures on spurt testing, and central position allowing for an aesthetic inset of the breast mound with minimal pedicle dissection.

The diameter of the lateral thoracic artery ranged from 1.5 to $2.5 \mathrm{~mm}$ (mean $=2 \mathrm{~mm}$ ), and vein diameter ranged from 2 to $3 \mathrm{~mm}$ (mean $=2.75 \mathrm{~mm}$ ) (-Table $\mathbf{1}$ ). In two cases, the lateral thoracic artery was beveled (case 3 ) and spatulated (case 4) to overcome size mismatch, with no adverse sequelae. There were no cases of vessel conversion. All patients had uncomplicated postoperative courses with no flap complications at outpatient review of up to 50 days (-Fig. 1).

\section{Discussion}

While advances in free flap technique have resulted in the evolution of the TRAM flap, with reduced donor-site morbidity and improved flap survival, the IM and thoracodorsal vessels have remained the recipient vessels of choice for many years. Recently, the IM perforators have also been used. ${ }^{10-12}$ Alternative options that have been described include the thoracoacromial $^{13}$ and circumflex scapular vessels. ${ }^{14}$

The thoracodorsal vessels were the traditional vessels of choice owing to their exposure as part of the axillary dissection. However, over the last decade, with the advent of sentinel lymph node biopsy, there has been a shift toward the IM vessels. ${ }^{15}$ Significant downsides of the thoracodorsal vessels include an 11 to $15 \%$ incidence of unusable vessels in delayed reconstruction as a result of radiation therapy and postoperative scarring. ${ }^{4,16}$ Moreover, its relatively lateral position in the axilla may impede aesthetic flap inset, and sacrifice of the thoracodorsal pedicle precludes use of the latissimus dorsi myocutaneous flap in the event of flap failure.

The IM vessels have been studied extensively. ${ }^{5-7}$ They are medially positioned with good caliber match for the DIEP or TRAM flaps. ${ }^{6}$ However, disadvantages include pain and risk of pneumothorax from rib resection, chest wall movement during respiration, and sacrifice of a potential vessel for coronary bypass. ${ }^{15}$ Compared with the IM vessels, preparation of the IM perforators is less invasive, avoiding the need to excise costal cartilage and preserving the IM vessels for coronary bypass. ${ }^{11}$ However, drawbacks include a small

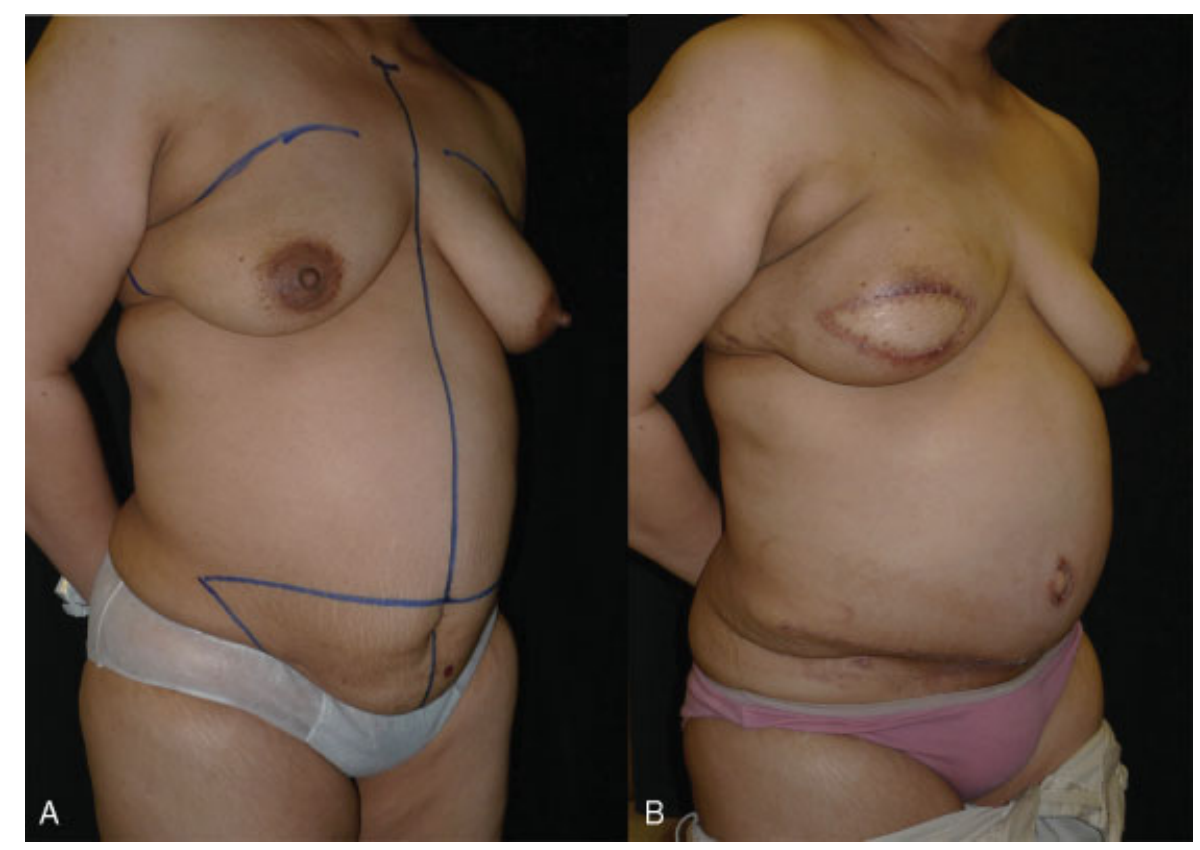

Fig. 2 A 45-year-old lady underwent skin-sparing mastectomy for retroareolar invasive ductal carcinoma. Immediate reconstruction with an ipsilateral free TRAM flap was performed. Review at postoperative day 50. 


\section{Lateral Thoracic Vessels in Breast Reconstruction Fong et al.}

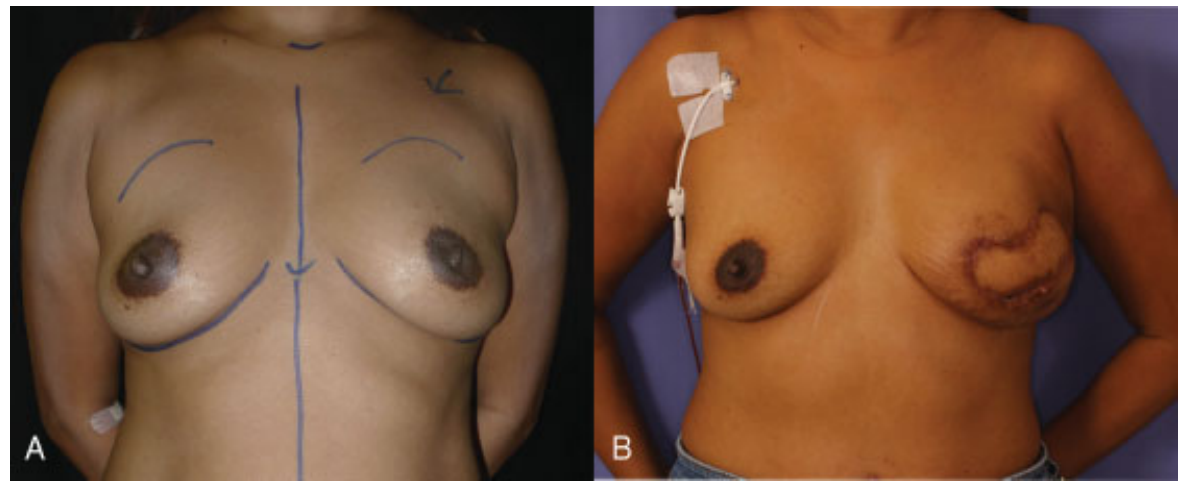

Fig. 3 A 46-year-old lady underwent skin-sparing mastectomy with sentinel node biopsy for invasive ductal carcinoma. Immediate reconstruction with an ipsilateral free TRAM flap was performed. Review at postoperative day 18.

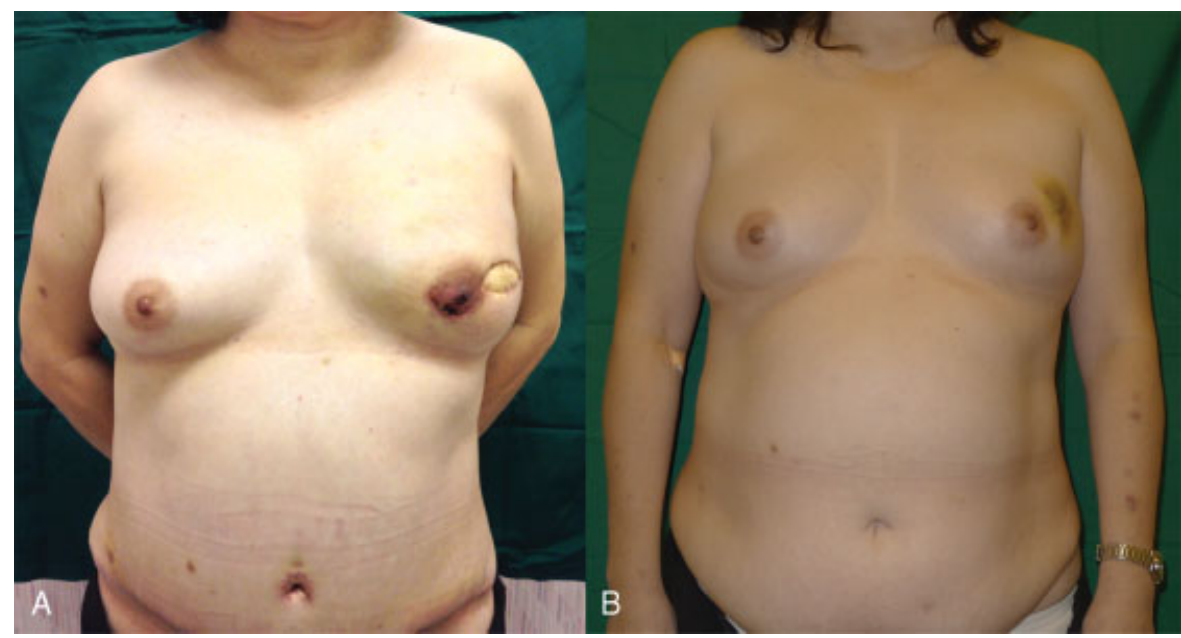

Fig. 4 A 57-year-old lady underwent nipple-sparing mastectomy for invasive ductal carcinoma. Immediate reconstruction with a contralateral DIEP flap was performed. Review at postoperative day 11.

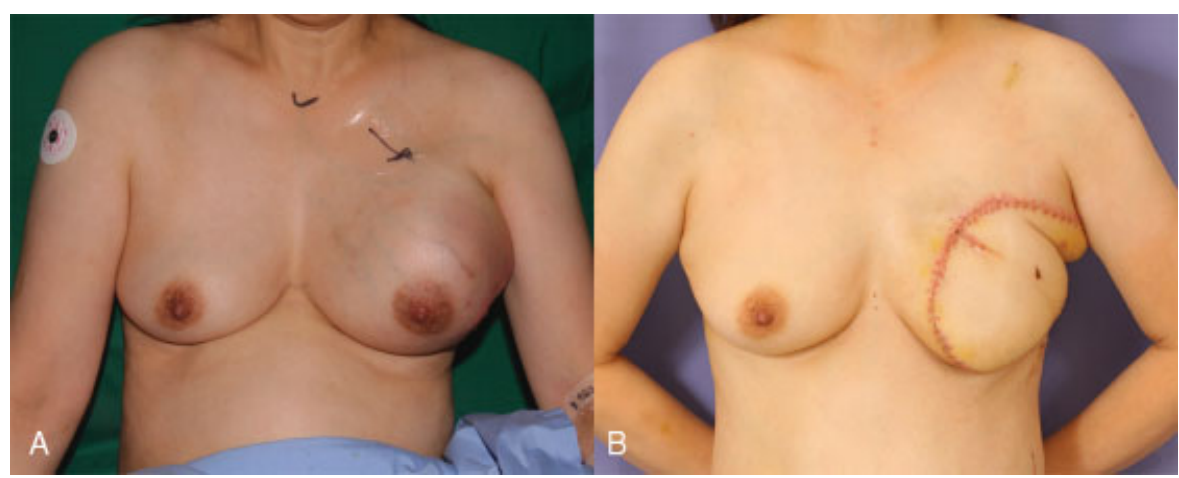

Fig. 5 A 52-year-old lady with malignant transformation of a phyllodes tumor underwent simple mastectomy. Immediate reconstruction with a contralateral pedicled TRAM flap was performed. Supercharging via the deep inferior epigastric vessels and lateral thoracic vessels was performed. Review at postoperative day 14.

Table 1 Patients, flap types and vessel diameters

\begin{tabular}{|l|l|l|l|l|l|l|l|l|}
\hline Patient & Age (y) & $\begin{array}{l}\text { Mastectomy } \\
\text { type }\end{array}$ & Side & Flap type & Anastomosis & $\begin{array}{l}\text { Vessel diameter } \\
\text { (artery/vein) }\end{array}$ & $\begin{array}{l}\text { Beveling/ } \\
\text { spatulation }\end{array}$ & \begin{tabular}{l} 
Complication \\
\hline 1
\end{tabular} \\
\hline 46 & SSM/SLNB & Left & Free TRAM, ipsilateral & ETE & $2 / 3 \mathrm{~mm}$ & - & None \\
\hline 2 & 45 & SSM/SLNB & Right & Free TRAM, ipsilateral & ETE & $2.5 / 3 \mathrm{~mm}$ & - & None \\
\hline 3 & 52 & SM & Left & $\begin{array}{l}\text { Supercharged TRAM, } \\
\text { contralateral }\end{array}$ & ETE & $1.5 / 2 \mathrm{~mm}$ & Beveling & None \\
\hline 4 & 57 & NSM & Left & DIEP, contralateral & ETE & $2 / 3 \mathrm{~mm}$ & Spatulation & None \\
\hline
\end{tabular}

Abbreviations: ETE, end-to-end; NSM, nipple-sparing mastectomy; SLNB, sentinel lymph node biopsy; SM, simple mastectomy; SSM, skin-sparing mastectomy. 


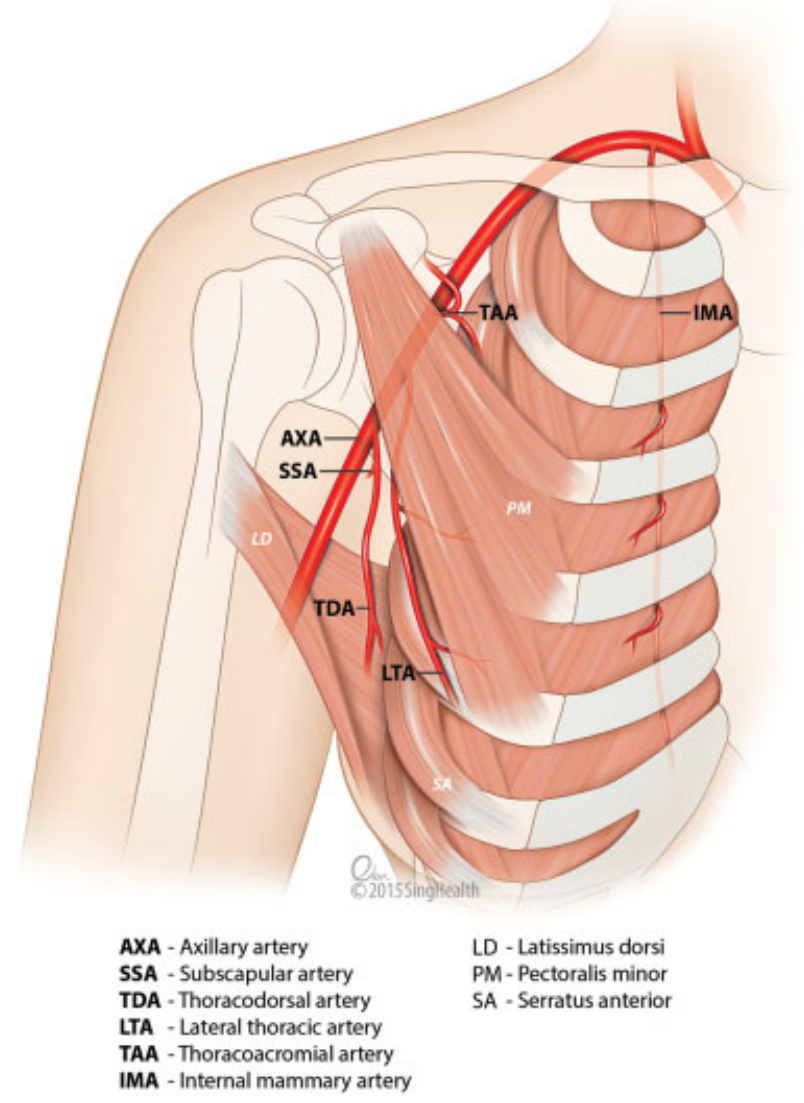

Fig. 6 Recipient vessels of the chest wall. The lateral thoracic artery is classically described as a branch of the second part of the axillary artery, under pectoralis minor. It is found on the lateral border of the pectoral muscles, close to the skin-sparing mastectomy defect.

artery caliber, with mean IM perforator artery external diameters ranging from 1.0 to $1.9 \mathrm{~mm} .^{10,16}$

Lantieri and colleagues described a technique to utilize the circumflex scapular vessels and demonstrated their results in 40 cases. However, dissection down to, and ligation of a branch to, teres major is required to attain sufficient pedicle length, and microscope positioning in the axilla can be suboptimal. ${ }^{14}$

Kompatscher and colleagues evaluated the descending pectoral branch of the thoracoacromial vessels in an anatomical and sonographic study. The vessels were found between the third and fourth ribs, positioned 9.0 to $10.4 \mathrm{~cm}$ from the midsternal line. A drawback is that a long donor pedicle may be required to reach a segment of good caliber match for the DIE vessels. ${ }^{17}$

\section{Anatomy of the Lateral Thoracic Vessels}

The lateral thoracic artery is classically described as a branch of the second part of the axillary artery (-Fig. $\mathbf{6}$ ). It descends on the serratus fascia, deep to pectoralis major, supplying the superior slips of serratus anterior, the pectoral muscles, and subscapularis. It also supplies the structures in the female breast, in particular the nipple areolar complex, and may anastomose with the IM artery. ${ }^{18-20}$

In their anatomical study of the axillary artery, Hattori and colleagues observed five distinct variations in the
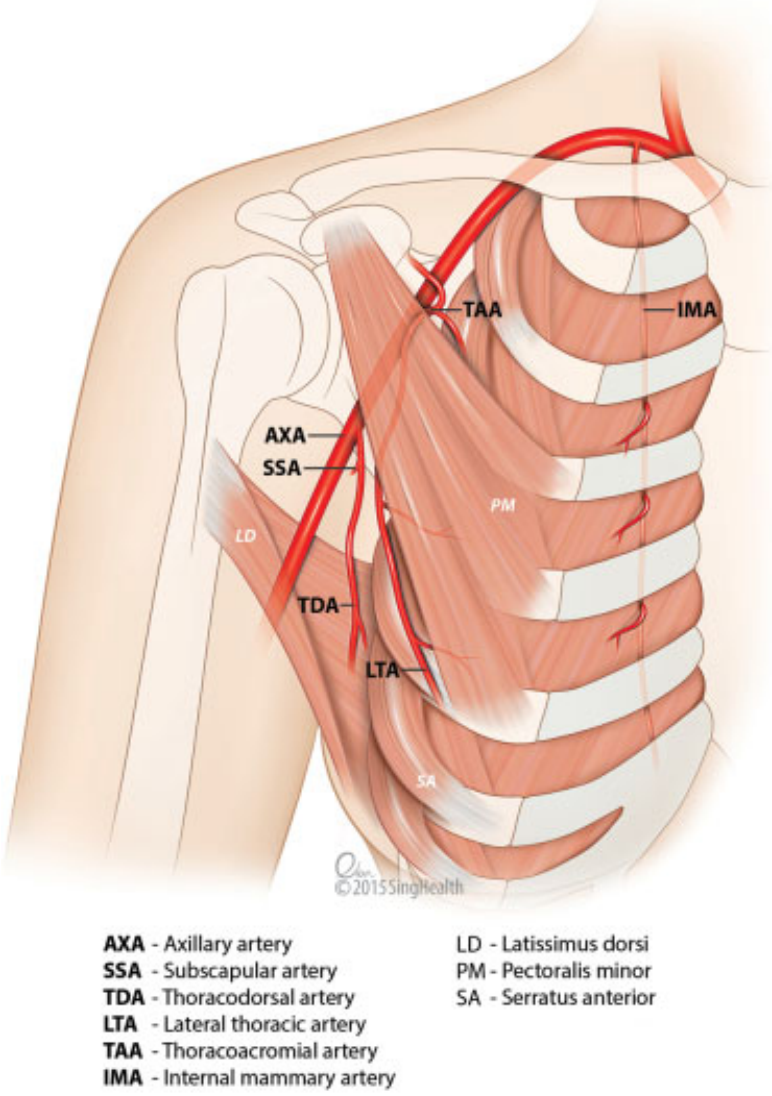

Fig. 7 Loukas et al found six morphological subtypes of the origin of the lateral thoracic artery. It was most commonly found $(67.6 \%$ of specimens) to be a branch of the thoracoacromial artery. Ultimate tissue distribution and proximity to pectoralis minor was consistent.

branching pattern of the subscapular and posterior circumflex humeral arteries in 41/62 upper extremities. The thoracoacromial artery was found consistently as a branch from the first or second part of the axillary artery. ${ }^{21} \mathrm{~A}$ recent anatomical study of 420 adult cadavers by Loukas et al showed that the lateral thoracic artery was present in $96.7 \%$ of cases. ${ }^{22}$ In their dissections, the origin of the lateral

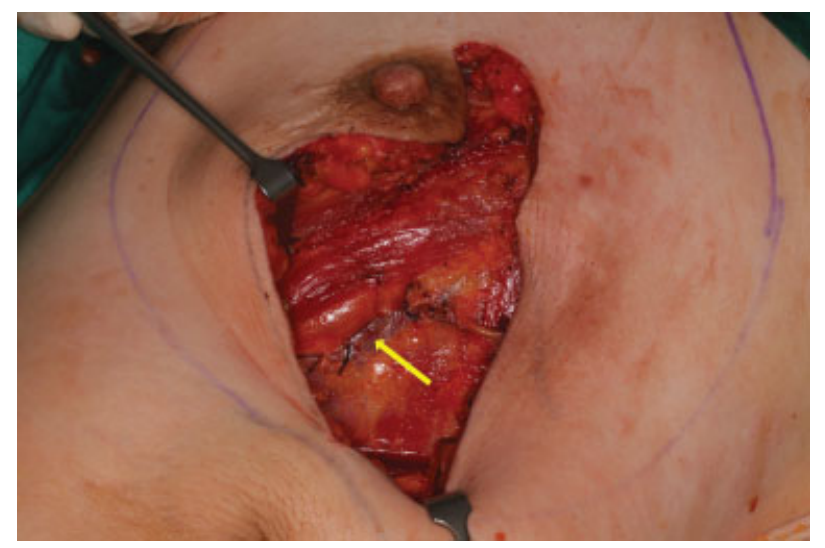

Fig. 8 The lateral thoracic vessels (arrow) are found lateral to pectoralis major, tracing the inferior border of pectoralis minor, on the serratus fascia. The vessels are exposed intraoperatively, with minimal site preparation required. 

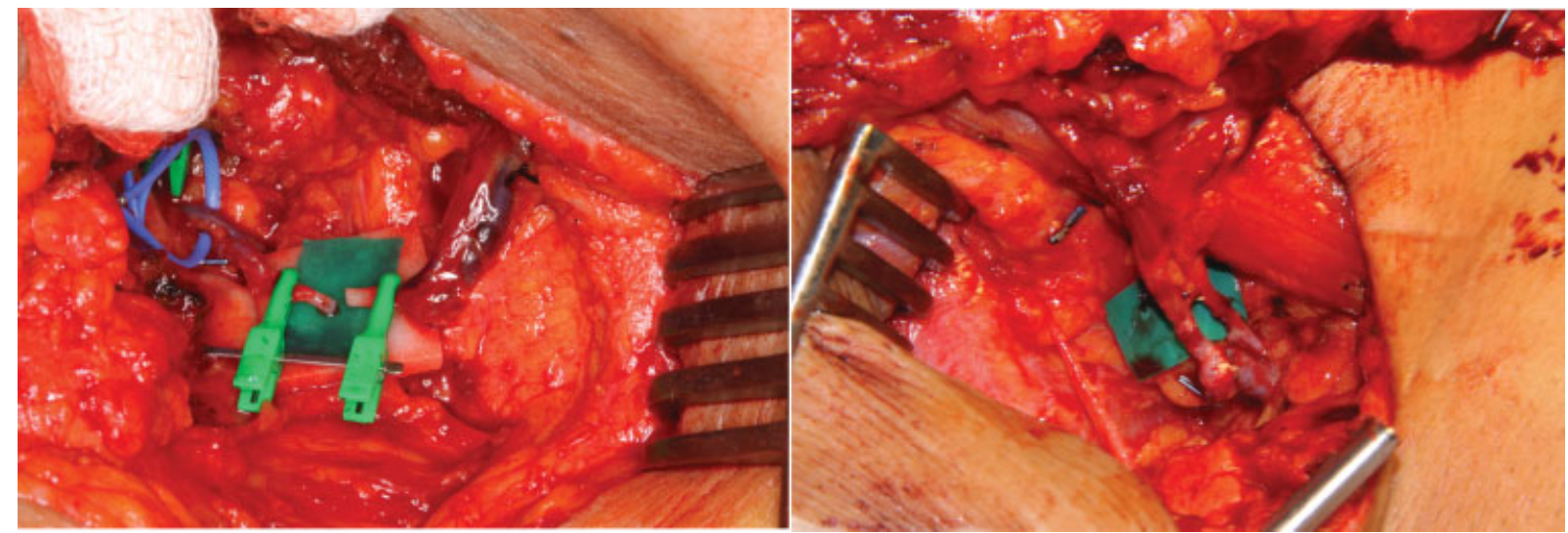

Fig. 9 Pre- and postanastomosis between the deep inferior epigastric and lateral thoracic vessels. Vessel caliber is usually a good match for the deep inferior epigastric vessels, although mismatch can be overcome with standard microsurgical techniques such as spatulation or beveling.

thoracic artery showed great morphological variety, which has also been highlighted by several case reports. ${ }^{23-25}$ The authors classified the vessel origin into six subtypes. Interestingly, the lateral thoracic artery was found most com-

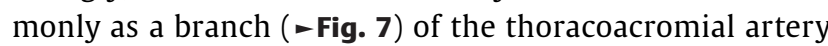
(67.6\% of specimens), and directly from the second part of the axillary artery in only $17 \%$. Despite the variable origin of the lateral thoracic artery, the ultimate tissue distribution was found to be consistent. In $90 \%$ of specimens, the vessel was found along the lateral border of pectoralis minor. ${ }^{22}$ Suffice to say that while many variations in the branching pattern of the axillary artery exist, the distal course of the lateral thoracic artery is consistent and it may be reliably found inferolateral to the pectoralis muscles.

In our experience, we have also found its distal course to be consistent in its position on the serratus fascia and proximity to pectoralis minor. If the vessel is preserved during resection, it can usually be found at the inferolateral border of pectoralis major, close to the center of the skin-sparing mastectomy defect (-Fig. 8). The central position of this vessel allows for easy preparation with the patient in the supine position. Ipsilateral or contralateral flap configurations may be easily inset. Vessel caliber is usually a good match to the deep inferior epigastric vessels (-Fig. 9), although proximal dissection on the serratus fascia will afford a longer recipient segment with larger caliber in the event of caliber mismatch or short pedicle length. Alternatively, standard microsurgical techniques such as vessel beveling or spatulation may be used.

\section{Conclusion}

Our cases have demonstrated the utility of the lateral thoracic vessels in free and supercharged TRAM flaps. Their intraoperative exposure saves time and minimizes vessel dissection. Its proximity to pectoralis major allows for medial placement of the breast mound and minimizes donor pedicle length. Use of this centrally located vessel spares the IM vessels for future coronary bypass, and the thoracodorsal pedicle of the latissimus dorsi flap. We believe that the lateral thoracic vessels are a useful, often-overlooked option in breast reconstruction, and propose that they are a useful alternative to the thoracodorsal or internal mammary vessels.

\section{Conflict of Interest}

The authors certify that they have no affiliations with or involvement in any organization or entity with any financial interest or nonfinancial interest in the subject matter or materials discussed in this article.

\section{Acknowledgments}

The authors would like to thank Mr. Evan Lim from the Singapore General Hospital for producing the medical illustrations in this article.

\section{References}

1 Banwell M, Trotter D, Ramakrishnan V. The thoracodorsal artery and vein as recipient vessels for microsurgical breast reconstruction. Ann Plast Surg 2012;68(5):542-543

2 Feng LJ. Recipient vessels in free-flap breast reconstruction: a study of the internal mammary and thoracodorsal vessels. Plast Reconstr Surg 1997;99(2):405-416

3 Guay NA. The thoracodorsal vessels are advantageous, reliable, and safe recipient vessels for free abdominal flap breast reconstruction. Ann Plast Surg 2012;68(5):539-541

4 Serletti JM, Moran SL, Orlando GS, Fox I. Thoracodorsal vessels as recipient vessels for the free TRAM flap in delayed breast reconstruction. Plast Reconstr Surg 1999;104(6):1649-1655

5 Damen TH, Morritt AN, Zhong T, Ahmad J, Hofer SO. Improving outcomes in microsurgical breast reconstruction: lessons learnt from 406 consecutive DIEP/TRAM flaps performed by a single surgeon. J Plast Reconstr Aesthet Surg 2013;66(8): 1032-1038

6 Murray AC, Rozen WM, Alonso-Burgos A, Ashton MW, GarciaTutor E, Whitaker IS. The anatomy and variations of the internal thoracic (internal mammary) artery and implications in autologous breast reconstruction: clinical anatomical study and literature review. Surg Radiol Anat 2012;34(2):159-165

7 Nahabedian M. The internal mammary artery and vein as recipient vessels for microvascular breast reconstruction. Ann Plast Surg 2012;68(5):537-538 
8 Klein S, Hoving S, Werker P, Russell N. Is there an indication for digital subtraction angiography in the assessment of irradiation-induced vascular damage before free flap surgery by the means of the internal mammary vessels? J Reconstr Microsurg 2014;30(1):47-52

9 Healy C, Allen RJ Sr. The evolution of perforator flap breast reconstruction: twenty years after the first DIEP flap. J Reconstr Microsurg 2014;30(2):121-125

10 Fansa H, Schirmer S, Cervelli A, Gehl HB. Computed tomographic angiography imaging and clinical implications of internal mammary artery perforator vessels as recipient vessels in autologous breast reconstruction. Ann Plast Surg 2013;71(5):533-537

11 Halim AS, Alwi AA. Internal mammary perforators as recipient vessels for deep inferior epigastric perforator and muscle-sparing free transverse rectus abdominis musculocutaneous flap breast reconstruction in an Asian population. Ann Plast Surg 2014;73(2): 170-173

12 Hamdi M, Blondeel P, Van Landuyt K, Monstrey S. Algorithm in choosing recipient vessels for perforator free flap in breast reconstruction: the role of the internal mammary perforators. Br J Plast Surg 2004;57(3):258-265

13 Harashina T, Takamatsu A. The thoracoacromial vessels as recipient vessels in microsurgery and supermicrosurgery: an anatomical and sonographic study. Plast Reconstr Surg 2006;118(1):279

14 Lantieri LA, Mitrofanoff M, Rimareix F, Gaston E, Raulo Y, Baruch JP. Use of circumflex scapular vessels as a recipient pedicle for autologous breast reconstruction: a report of 40 consecutive cases. Plast Reconstr Surg 1999;104(7):2049-2053

15 Saint-Cyr M, Youssef A, Bae HW, Robb GL, Chang DW. Changing trends in recipient vessel selection for microvascular autologous breast reconstruction: an analysis of 1483 consecutive cases. Plast Reconstr Surg 2007;119(7):1993-2000

16 Saint-Cyr M, Chang DW, Robb GL, Chevray PM. Internal mammary perforator recipient vessels for breast reconstruction using free TRAM, DIEP, and SIEA flaps. Plast Reconstr Surg 2007;120(7): 1769-1773

17 Kompatscher P, Manestar M, Schuster A, Lang A, Beer GM. The thoracoacromial vessels as recipient vessels in microsurgery and supermicrosurgery: an anatomical and sonographic study. Plast Reconstr Surg 2005;115(1):77-83

18 Sinnatamby CS. Last's Anatomy: Regional and Applied. Edinburgh: Churchill Livingstone; 2006

19 Moore KL, Agur AMR. Essential Clinical Anatomy. Philadelphia, PA: Lippincott Williams \& Wilkins; 1995

20 Williams PL, Warwick R, Dyson M, Bannister LH. Gray's Anatomy. 37th ed. Norwich: Churchill Livingstone; 1989

21 Hattori Y, Doi K, Sakamoto S, Satbhai N. Anatomic variations in branching patterns of the axillary artery: a multidetector-row computed tomography angiography study. J Reconstr Microsurg 2013;29(8):531-536

22 Loukas M, du Plessis M, Owens DG, et al. The lateral thoracic artery revisited. Surg Radiol Anat 2014;36(6):543-549

23 Srimathi T. Abnormal branching pattern of the axillary artery - a case report. Int J Basic Med Sci 2011;2:73-76

24 Chitra PS, Anandhi V. A unique variatoin in branching pattern of axillary artery. Int J Anat Var 2013;6:1-3

25 Agrawal D, Singh N, Mohanty BB, Chinara PK. Variation in the branching pattern of axillary artery - a case report. Int J Anat Var 2013;6:31-33 